\title{
Tests of the conditioned reinforcement value of sequential stimuli in pigeons
}

\author{
ROBERT A. HANCOCK, JR. \\ Kansas State University, Manhattan, Kansas 66502
}

\begin{abstract}
Egger and Miller (1962) hypothesized that the conditioned reinforcing value of stimuli depends on their information value. Egger and Miller and others have tested this hypothesis by comparing the conditioned reinforcing value of S1 and S2 following S1-S2-reward training. However, none of these experiments have controlled for differential generalization of conditioned reinforcement value from training to comparison tests. That is, the $S 1$ cue pattern during the conditioned reinforcement tests has been very similar to the S1 cue pattern of training, while the training and test S2 cue patterns have been quite dissimilar. In Experiment 1, pigeons in a procedure unconfounded by differential generalization produced S2 reliably more frequently than $\mathrm{S} 1$, and pigeons in a confounded procedure produced S1 somewhat more frequently than S2. A significant groups $X$ stimuli interaction was attributed to differential stimulus generalization from training to test for S1 and S2 in the confounded condition. In Experiment 2, pigeons in an unconfounded procedure again produced S2 reliably more frequently under a different testing procedure. The results are interpreted as demonstrating that, following S1-S2-food training trials, $\mathrm{S} 2$ is the more effective conditioned reinforcer in unconfounded conditions. A reconceptualization of the information hypothesis is shown to be consistent with these results.
\end{abstract}

A pure tone is sounded before each of several deliveries of a food pellet to a hungry rat. Later, each time the rat presses a bar, the tone follows. The frequency of responding increases; barpressing is positively reinforced by the tone. This example illustrates the phenomenon of conditioned or secondary reinforcement. A previously neutral stimulus, by virtue of having been followed by a reward (e.g., food), acquires the capacity to positively reinforce antecedent responses; the stimulus has become a positive conditioned reinforcer.

Egger and Miller's (1962, 1963; Miller, 1961) information hypothesis is an attempt to specify the conditions under which reinforcement occurs and previously neutral stimuli acquire reinforcing properties. Egger and Miller (1963) hypothesized that "reinforcement occurs primarily at the point at which information is delivered.... Indeed, the arrival of information about primary reward may be the only occasion when reinforcement occurs"' (p. 132).

Egger and Miller (1962) defined "information" with respect to the procedures outlined in Figure 1. The S2 redundant and S2 informative procedures

This article is based on a portion of a dissertation submitted to Kansas State University in partial fulfillment of the requirements for the PhD degree. The author wishes to thank his committee for their cooperation and most especially Charles C. Perkins for his persistent encouragement. The research reported was supported by NSF Grant DB 27595 and NIMH Training Grant 5T01MH 08359 awarded to Kansas State University. Reprint requests should be sent to the author at the Department of Psychology, Northwest Missouri State University, Maryville, Missouri 64468 . were presented to different groups of rats. In the S2 redundant procedure, $S 1$ preceded and overlapped S2 on all trials, and this sequence was always followed

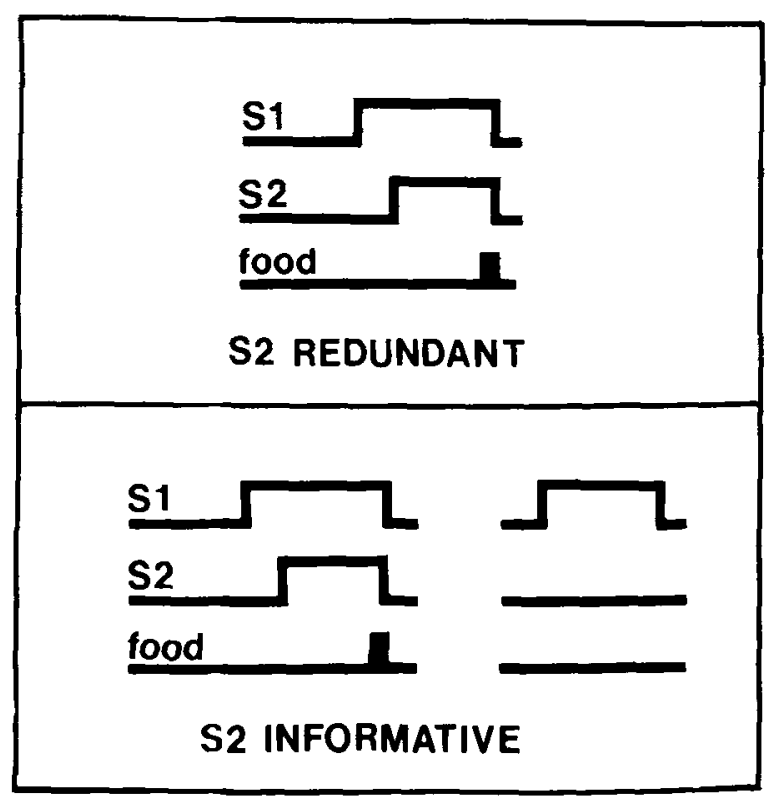

Figure 1. A summary of the $S 2$ redundant (top) and $S 2$ informative (bottom) procedures. The $\mathbf{S 2}$ redundant procedure consisted of trials in which the onset of S1 was followed .5 sec later by the onset of S2; 1.5 sec later, food was delivered. Both stimuli overlapped the delivery of food by .25 sec and terminated together. The 52 informative procedure consisted of these S1-S2-food trials interspersed with trials of 2 sec of $S 1$ alone, such that $S 1$ was followed by food $55 \%$ of the time. 
by food. Egger and Miller (1962) called S1 'informative" and S2 "redundant" and predicted that under these conditions "S1 should be an effective secondary reinforcer [and] S2 should acquire little or no secondary reinforcing strength" (1962, p. 97). In their S2 informative procedure, S1-alone trials were interspersed with S1-S2-food trials. Egger and Miller called S1, under these conditions, "unreliable" and S2 "informative" and predicted that this informative S2 would "be a considerably more effective secondary reinforcer" than a redundant S2 (1962, p. 98).

A number of experiments (Davis \& Oliphant, 1968; Egger \& Miller, 1962; McCausland, Menzer, Dempsey, \& Birkimer, 1967; Seligman, 1966; Thomas, Berman, Serednesky, \& Lyons, 1968) have shown that an informative $\mathrm{S} 1$ is a more effective conditioned reinforcer than a redundant $\mathbf{S 2}$. However, the interpretation of all of these experiments is complicated by a confounding variable. (Comparisons of redundant and informative S2s are considered in the general discussion section.)

Tests of the conditioned reinforcement value of stimuli following S2 redundant training have been based on the assumption that the conditioned reinforcing properties of training stimuli will generalize equally to the test situation. However, Borgealt, Donahoe, and Weinstein (1972) and Davis and Oliphant (1968) have suggested that, following the S2 redundant training procedure, there is greater generalization of conditioned reinforcing properties of S1 than of S2 from training to test. The background or contextual conditions during the conditioned reinforcement tests previously employed have been identical or very similar to the intertrial interval (ITI) conditions during training. S1 follows the same stimulus conditions and occurs in the same context in training and testing. However, S2 follows different stimulus conditions and occurs in a different context in training and test. Presumably, as the similarity of training and test contexts decreases, generalization of the effects of training to testing also decreases. Therefore, a greater proportion of S1's conditioned reinforcement value would generalize from training to test because S1's context changes very little between training and test and S2's context changes much more. The effect of this differential change in context will be referred to as a differential generalization decrement or differential generalization of conditioned reinforcing properties.

A number of different procedures have been employed to compare informative S1s to redundant S2s. However, all these procedures confound stimuli (S1 vs. S2) with differential generalization of conditioned reinforcing properties. Egger and Miller (1962) and Seligman (1966) both employed a training procedure in which S1 preceded, overlapped, and terminated with S2, as shown in Figure 1. In test, S1 and S2 in- dividually followed leverpresses. McCausland et al. (1967) and Thomas et al. (1968) employed training procedures in which S1 termination and S2 onset were simultaneous. Conditioned reinforcement tests again consisted of making $\mathrm{S} 1$ and $\mathrm{S} 2$ individually contingent on responding under stimulus conditions that preceded only S1 in training. As previously noted, Davis and Oliphant (1968) recognized the differential generalization decrement problem. They attempted to circumvent this problem by employing a trace conditioning procedure. They employed 1-sec stimuli with 5 -sec intervals between the presentation of S1 and S2 and 5-sec intervals between S2 and food. Thus, external environmental cues preceding $S 1$, between $\mathrm{S} 1$ and S2, and between S2 and food were all "identical." However, the stimulus trace of S1 may have been present during $S 2$ in training. In testing, the stimulus trace accompanying S1 was the same trace that had accompanied S1 in training, that is, S1 followed the ITI in both cases. A different trace accompanied S2 in training and test; S2 followed S1 in training and the ITI in test. Presumably, all of these procedures produce differential generalization decrements favoring S1. In Davis and Oliphant's procedure, differential generalization could result from the stimulus trace of conditions preceding the trace intervals. In McCausland et al.'s and Thomas et al.'s procedures, the stimulus trace of immediately preceding stimuli would produce differential generalization decrements, and in Egger and Miller's and Seligman's procedures, differential decrements would be produced by both the immediate context and the stimulus trace of antecedents.

It is interesting to note in this regard that Baker (1972) compared S2 redundant procedures in which the degree of overlap of S1 over S2 was varied. Baker found that, as overlap decreased, the conditioned reinforcing effect of $S 1$ relative to that of $S 2$ also decreased.

\section{EXPERIMENT 1}

Experiment 1 assessed the conditioned reinforcing properties of S1 and S2 following S2 redundant training in two groups. The confounded group's procedure replicated that of Thomas et al. (1968). This procedure presumably confounded differential generalization decrement with stimulus position. The procedure for the unconfounded group was designed to control for differential generalization decrements. In both groups of pigeons, response-contingent S1S2 sequences were produced on a variable-interval (VI) schedule. The conditioned reinforcement test that followed training consisted of periods during half of which responding produced only S1 and during the other half of which responses produced only S2. The stimulus produced more often was assumed to be the more effective conditioned reinforcer. 
Of necessity, S2 follows a stimulus other than S1 in a conditioned reinforcement test. In test, decrements in S2's acquired properties cannot be eliminated because of the unavoidable difference between stimulus conditions preceding $\mathbf{S} 2$ on training and test trials. Therefore, the confounding of differential generalization with stimuli (S1 vs. S2) was eliminated by employing a procedure which also changed the stimulus conditions preceding S1. This required introducing a change in the ITI conditions between training and test.

Equal similarity of S1 and S2 in test to S1 and S2 in training, that is, equal generalization, was achieved in the unconfounded group by using different colored key lights as S2, S1, and the VI schedule (the functional ITI) on which the S1-S2 sequence was contingent (see Figure 2). These stimuli were completely counterbalanced across subjects. The stimulus condition preceding $S 1$ and S2 in test was a white key for all subjects. Thus, between training and test, there was a change in context for S1 and S2 that was counterbalanced across subjects and therefore equated for the group. Although the properties acquired by S1 and S2 in training presumably did not generalize completely to testing due to changes in context, the context changes, and presumably any generalization decrement, were the same for both.

The procedure for the confounded group presumably produced differential generalization decrements. S1 and S2 were colors, while the VI schedule was signaled by a white light, as shown in Figure 2. Because the same conditions preceded S1 in training and test but different conditions preceded $\mathrm{S} 2$ in these two phases, greater generalization decrement from training to test is expected for S2. (A group in Thomas et al.'s first experiment, following nearly identical training, produced $\mathrm{S} 1$ significantly more often than S2 in the test.)
TRA I N I N G

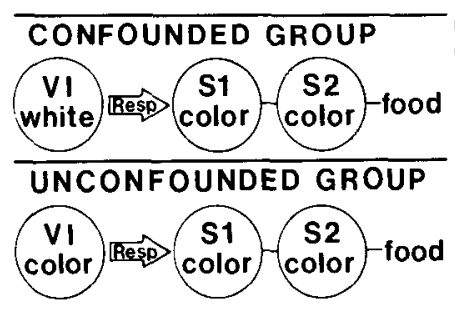

TE S T I N G

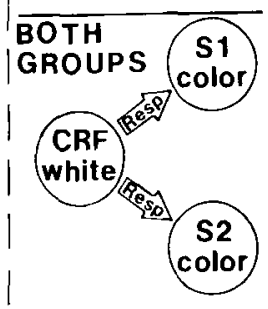

Figure 2. An outline of the confounded and unconfounded procedure in Experiment 1. During pretraining, both groups were trained to respond to a white key. During training, S1-S2 sequences, some of which were followed by food, were response dependent. During testing, individual presentations of $\mathbf{S 1}$ and $\mathbf{S 2}$, without food, were response dependent. The difference in procedure for the two groups is that the key colors preceding $S 1$ and S2 change from training to testing for the unconfounded group, but only the key color preceding $\mathbf{S} 2$ changes in the confounded group.

\section{Method}

Subjects. Data are reported from 35 experimentally naive pigeons which were obtained from a local supplier and maintained at $75 \%$ of free-feeding weight in individual cages in a continually illuminated room. An additional pigeon, which had been assigned to the unconfounded group, became ill during pretraining and was dropped from the experiment.

Apparatus. Two identical Grason-Stadler animal chests were equipped with homemade machine-gray intelligence panels and false floors. The experimental space produced was $32 \mathrm{~cm}$ from the panel to the back wall, $37 \mathrm{~cm}$ from side to side, and $30 \mathrm{~cm}$ high. Two translucent Gerbrands pigeon keys, $21 \mathrm{~cm}$ above floor level (floor to center) and $5 \mathrm{~cm}$ apart (center to center), were located symmetrically around the vertical center line of each panel. Only keypecks of at least .10 N were recorded, produced feedback clicks, or affected contingencies. A feedback relay for each key was located behind the panel beneath the key. The right key was covered with gray tape for this experiment; only the left key was functional. The Lehigh Valley Electronics grain feeder, which delivered a $50 \%$ milo and $50 \%$ wheat mixture, was located behind a $5.0 \times 4.5 \mathrm{~cm}(\mathrm{~W} \times \mathrm{H})$ aperture centrally located $3.3 \mathrm{~cm}$ above floor level. Stimuli were projected onto the response keys by Industrial Electronics Engineers in-line projectors, which provided solid white, amber, red, and green key stimuli. The houselight, a 3-W $115-\mathrm{V}$ bulb in series with a $1-\mathrm{k} \Omega$ resistor covered by an $8-0 z$ Styrofoam cup, was mounted $21 \mathrm{~cm}$ above the floor on the wall of the compartment opposite to the key. Ventilating fans and white noise sources behind intelligence panels produced a masking noise of about $90 \mathrm{~dB}$ ( $\mathrm{C}$ scale of a General Radio $\mathrm{Co}$. sound-level meter). The animal chests were located inside individual fiberboard cubicles. Control and recording equipment was in an adjoining room.

Procedure. Subjects were randomly assigned, in equal numbers, to groups and to conditions within groups before the experiment began. The houselight was on at all times except during 2 -sec presentations of the illuminated feeder and during blackouts in the conditioned reinforcement test. All variable-interval schedules in the present experiment were constructed from Fleshler and Hoffman (Note 1) schedules. The subjects were feeder habituated and then hand-shaped to peck a white stimulus on the left key in one to three sessions. During each of the following 12 sessions, the subjects earned 30 grain presentations on a variable-interval (VI) schedule for responses to the white key. Grain was available on a VI 15-sec schedule during the first 2 sessions and a VI 60-sec schedule during the last 10 .

During the first training session, the subjects earned $30 \mathrm{~S} 1-\mathrm{S} 2-$

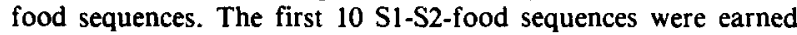
on a V1 60 -sec schedule. Then $20 \mathrm{S1-S2}$ sequences, a random $50 \%$ of which were followed by grain, were earned on a VI $30-\mathrm{sec}$ schedule. Finally, $30 \mathrm{~S} 1-\mathrm{S} 2$ sequences, a random third of which were followed by grain, were earned on a VI $20-\mathrm{sec}$ schedule. During each of the five following sessions, each bird earned $90 \mathrm{~S} 1-\mathrm{S} 2$ sequences, a random third of which were followed by grain. In the 6 days of training, each subject earned a total of $180 \mathrm{S1}$-S2food sequences. Note that once an S1-S2 sequence had been initiated, responding was not required to advance the sequence.

S1 and S2 were each $1 \mathrm{sec}$ in duration with a 0 -sec interstimulus interval for both groups. Unlike Egger and Miller (1962) and Seligman (1966), but similar to McCausland et al. (1967) and Thomas et al. (1968), the S1-S2 sequence was not overlapping. The confounded group earned S1-S2 sequences for responses to a white key; the unconfounded group earned S1-S2 sequences for responses to a colored key. This difference in stimulus conditions during the VI was the only difference in procedures for the two groups. Column A of Tables 1 and 2, which summarize some aspects of the procedure and the results for individual subjects in the confounded and unconfounded groups, respectively, shows the color of the key during the VI S1 and S2 for each subject.

A single test session, during which grain was never available, immediately followed (same day) the completion of the last training session. Responses to a white key light produced either $1 \mathrm{sec}$ 
of $\mathrm{S} 1$ or $1 \mathrm{sec}$ of $\mathrm{S} 2$ on a continuous reinforcement (CRF) schedule. However, each presentation of S1 and S2 was followed by a $1-\mathrm{sec}$ period during which responses to the white key had no effect on the contingency. This "dead" period, which Thomas et al. employed to ensure that the test would measure only the reinforcing properties of the stimuli, prevented bursts of responses

Table 1

A Summary of Some Aspects of the Procedure and Results for the Confounded Group in Experiment 1

\begin{tabular}{|c|c|c|c|}
\hline \multirow[b]{2}{*}{ Subject } & \multirow{2}{*}{$\begin{array}{l}\text { Training } \\
\text { Column A }\end{array}$} & \multicolumn{2}{|c|}{ Testing } \\
\hline & & Column B & Column C \\
\hline $\mathrm{C}_{1}$ & $\mathrm{~W} / \mathrm{A} / \mathrm{R}$ & 8.10 & 8.55 \\
\hline $\mathrm{C} 2$ & $W / R / A$ & 8.65 & 8.70 \\
\hline $\mathrm{C} 3$ & W/A/R & 7.35 & 7.20 \\
\hline $\mathrm{C} 4$ & $\mathrm{~W} / \mathrm{R} / \mathrm{A}$ & 6.89 & 6.89 \\
\hline C 5 & W/G/A & 10.42 & 10.58 \\
\hline $\mathrm{C} 6$ & W/G/R & 9.15 & 9.25 \\
\hline $\mathrm{C} 7$ & W/G/A & 9.00 & 8.05 \\
\hline C 8 & $\mathrm{~W} / \mathrm{G} / \mathrm{R}$ & 6.55 & 6.05 \\
\hline C 9 & $W / R / G$ & 8.90 & 8.85 \\
\hline C 10 & W/A/G & 8.45 & 9.80 \\
\hline C 11 & $W / R / G$ & 7.25 & 5.95 \\
\hline C 12 & W/A/G & 5.45 & 6.30 \\
\hline C 13 & $\mathrm{~W} / \mathrm{A} / \mathrm{R}$ & 9.50 & 7.64 \\
\hline C 14 & W/R/A & 8.00 & 7.93 \\
\hline C 15 & $\mathrm{~W} / \mathrm{G} / \mathrm{A}$ & 5.25 & 4.75 \\
\hline C 16 & $\mathrm{~W} / \mathrm{G} / \mathrm{R}$ & 8.60 & 9.15 \\
\hline C 17 & $W / R / G$ & 5.50 & 5.05 \\
\hline C 18 & W/A/G & 6.55 & 6.70 \\
\hline Mean & & 7.75 & 7.63 \\
\hline
\end{tabular}

Note-Column $A=$ key light colors signaling the $V I, S 1$, and $S 2$ (presented as VI/S1/S2: $G=$ green, $A=$ amber, $R=$ red). Col . umn $B=$ mean number of $S 1$ stimuli produced per 30 -sec period. Column $C=$ mean number of $S 2$ stimuli produced per 30 -see period.

Table 2

A Summary of Some Aspects of the Procedure and Results for the Unconfounded Group in Experiment 1

\begin{tabular}{|c|c|c|c|}
\hline \multirow[b]{2}{*}{ Subject } & \multirow{2}{*}{$\begin{array}{c}\text { Testing } \\
\text { Column A }\end{array}$} & \multicolumn{2}{|c|}{ Testing } \\
\hline & & Column B & Column C \\
\hline UC 1 & $G / A / R$ & 8.00 & 8.05 \\
\hline UC 2 & G/R/A & 6.10 & 6.90 \\
\hline UC 3 & G/A/R & 9.20 & 9.45 \\
\hline UC 4 & G/R/A & 10.50 & 10.50 \\
\hline UC 5 & $\mathrm{R} / \mathrm{G} / \mathrm{A}$ & 6.42 & 6.00 \\
\hline UC 6 & $\mathrm{~A} / \mathrm{G} / \mathrm{R}$ & 6.65 & 7.50 \\
\hline UC 7 & $\mathbf{R} / \mathbf{G} / \mathbf{A}$ & 7.00 & 7.85 \\
\hline UC 8 & $A / G / R$ & 6.00 & 6.50 \\
\hline UC 9 & $A / R / G$ & 6.90 & 6.85 \\
\hline UC 10 & R/A/G & 4.36 & 4.86 \\
\hline UC 11 & $A / R / G$ & 6.60 & 6.90 \\
\hline UC 12 & G/A/R & 7.55 & 8.40 \\
\hline UC 13 & $\mathbf{G} / \mathbf{R} / \mathbf{A}$ & 7.15 & 8.60 \\
\hline UC 14 & $\mathrm{R} / \mathrm{G} / \mathrm{A}$ & 6.64 & 7.71 \\
\hline UC 15 & $A / G / R$ & 6.70 & 7.60 \\
\hline UC 16 & $A / R / G$ & 8.50 & 8.22 \\
\hline UC 17 & R/A/G & 8.05 & 9.05 \\
\hline Mean & & 7.20 & 7.70 \\
\hline
\end{tabular}

Note-Column $A=$ key light colors signaling the $V I, S 1$, and $S 2$ (presented as VI/S1/S2: $G=$ green, $A=$ amber, $R=$ red). Column $B=$ mean number of $S I$ stimuli produced per 30 -sec period. Column $C=$ mean number of $S 2$ stimuli produced per 30 -sec period. elicited during presentation of S1 and S2 from producing further presentations of the stimuli.

The subjects were given $30 \mathrm{sec}$ following the first presentation of either stimulus to earn subsequent presentation of that same stimulus. Then the chamber was darkened for $10 \mathrm{sec}$. At the end of this blackout, the houselight and white key light came on again for another test period.

Testing was continued for a maximum of 4030 -sec periods, 20 in which pecks produced $\mathrm{S} 1$ and 20 in which they produced $\mathbf{S 2}$. Order of test effects was controlled by the presentation of periods in the order S1-S2-S2-S1-S2-S1-S1-S2, cycled five times and counterbalanced across subjects within groups. If, after completion of the first four test periods (two of S1 and two of S2), a subject failed to respond for $180 \mathrm{sec}$, testing was terminated. When testing was terminated before the completion of 40 periods, only data from completed blocks of four periods were analyzed. For example, if a subject failed to respond after completing 10 periods, only data from the first 8 were analyzed. The procedure differs slightly from Thomas et al.'s with respect to session length, counterbalancing procedure, and termination criterion.

\section{Results}

The 35 subjects each maintained responding throughout pretraining, training, and at least one block of four test trials. Columns B and C of Tables 1 and 2 show the mean number of stimuli produced per 30 sec test period for each subject.

The confounded group produced S1 more frequently than $\mathrm{S} 2$, an average of 7.75 and 7.63 times, respectively, while the unconfounded group produced S2 more frequently than S1, an average of 7.70 and 7.20 times, respectively, per 30 -sec test period, as shown in Tables 1 and 2. A weighted means ANOVA (Winer, 1971) revealed that, between the groups, there was no difference in the mean number of stimuli produced $[F(1,33)<1]$ and, within the groups, $\mathrm{S} 2$ (mean $=7.66$ ) was not produced more frequently than $S 1$ (mean $=7.51$ ) overall $[F(1,33)=3.088, p>$ $.08]$. (All $p$ values reported are for two-tailed tests.) However, there was a significant groups $\times$ stimuli interaction $[F(1,33)=8.079, p<.008]$. This interaction is attributable to a differential generalization decrement within the confounded group. F tests for simple main effects (Winer, 1971) revealed that, within the unconfounded group, S2 was produced significantly more often than $S 1[F(1,33)=5.254$,

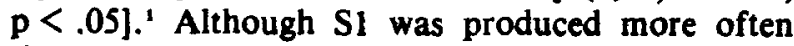
than $\mathrm{S} 2$ within the confounded group, this difference was not significant $[F(1,33)<1]$.

\section{Discussion}

Experiment 1 provides direct evidence that, when confounds are eliminated, $\mathbf{S 2}$ is a more effective conditioned reinforcer than $S 1$ following training with S1-S2-reward sequences. These results are contrary to predictions of Egger and Miller's information hypothesis as presently formulated. Second, the speculation that previous results in which an informative SI was a more effective conditioned reinforcer than a redundant $\mathrm{S} 2$ were a result of differential generalization of conditioned reinforcing properties has 
been given direct empirical support for the first time. This reconciles the results of those experiments in which S1 was a stronger conditioned reinforcer than $\mathrm{S} 2$ with the present results.

Although there was a significant groups $\times$ stimuli interaction, which was attributed to a differential generalization decrement in the confounded group, the confounded group did not show a significant S1 preference. Thomas et al. (1968) found that 18 of 20 birds that were tested after 180 S1-S2-food sequences showed an S1 preference. In the present experiment, 10 of 17 birds in the confounded group showed an $\mathrm{S} 1$ preference. This difference may reflect minor differences in the procedures employed.

In the experiments reported here, S1 and S2 were always colors; Thomas et al. employed a green key light and white vertical line on a black background as stimuli. However, it seems more likely that a difference in testing procedures was responsible for the failure to find a reliable S1 preference. Thomas et al. employed at least three stimuli in all their conditioned reinforcement tests: S1, S2, and one or more control stimuli. In the present experiment, only two stimuli (S1 and S2) were employed during tests. When testing in a region of low discriminability of wavelength, Marsh (1967) found that pigeons produced flatter generalization gradients with two stimuli than they did with three stimuli. Marsh's data suggest that, even though there was a generalization decrement, the procedure employed here minimized differential generalization in testing by producing relatively flat generalization gradients.

\section{EXPERIMENT 2}

Experiment 1 demonstrated that $\mathbf{S} 2$ is a more effective conditioned reinforcer following S1-S2-food training trials when confounds are eliminated. Experiment 2 was designed to determine if this same effect would be obtained with a choice test for conditioned reinforcement.

\section{Method}

Subjects. Twelve experimentally naive pigeons obtained from a local supplier were maintained at $75 \%$ of free-feeding weight in individual cages in a continually illuminated room.

Apparatus. The apparatus was the same as that used in Experiment 1 , except that the right key was uncovered. Both keys were functional.

Procedure. All subjects were feeder habituated and then trained in 3 sessions to (auto)peck the response keys. During the next 10 sessions, response tendencies were strengthened and equalized to the two keys by the following schedule. Both keys were illuminated white; responses to either one of the keys occasionally produced $2 \mathrm{sec}$ of grain. At the end of each 2 -sec interval, there was an equal and constant probability that the contingency would be instituted on either key, that is, that a response on one of the keys would produce grain. Once the contingency was instituted on either key, the program stopped advancing until the contingency was met. This schedule is identical to a concurrent variable-interval (CONC VI-VI) schedule in which both VI tapes are stopped whenever the contingency is set up (Stubbs \& Pliskoff, 1969). During the first concurrent session, the probability that grain would be set up on each key at the end of each 2-sec interval while the timers were running was .20 . That is, $\mathrm{p}$ (grain would be set up on the right key) $=\mathrm{p}($ grain would be set up on the left $\mathrm{key})=.20 / 2 \mathrm{sec}$ (approximately a CONC VI $10 \mathrm{sec}$ VI $10 \mathrm{sec}$ ). During the second session, $\mathrm{p}(\mathrm{grain}$ on the left $)=\mathrm{p}(\mathrm{grain}$ on the right $)=.04 / 2 \mathrm{sec}$ (approximately a CONC VI $60 \mathrm{sec}$ VI $60 \mathrm{sec}$ ). Each of the 10 concurrent constant probability sessions ended after 60 grain presentations.

During training, S1-S2 stimulus sequences, $50 \%$ of which were followed by $2 \mathrm{sec}$ of grain, were contingent on a concurrent constant probability schedule in which the probability that a sequence would be set up at the end of each 2 -sec interval was .10 on each key. S1-S2 sequences earned on one key were presented only on that key while the other key was dark. Sixty sequences were earned on each key in each session. A random 30 of the 60 sequences on each key were followed by grain for a total of 60 grain presentations per session. Note that once a sequence had been initiated, responding was not required either to advance the sequence or to produce grain.

The stimuli provided during the concurrent schedule, S1 and S2 for each subject, are shown in Column A of Table 3. Counterbalancing of colors across subjects produces equal stimulus changes between training and test when $\mathrm{S} 1$ and $\mathrm{S} 2$ follow white choice stimuli. Presumably, this results in equal generalization decrements of properties acquired by $S 1$ and $S 2$ in training. That is, the generalization decrement should be the same for $\mathrm{S} 1$ and for $\mathrm{S} 2$. S1 and S2 were each $4 \mathrm{sec}$ in duration with a 0 - $\mathrm{sec}$ interstimulus interval. There were four training sessions on successive days for a total of 480 S1-S 2 sequences, 240 of which were followed by grain.

The test session, which followed the last training session by $24 \mathrm{~h}$, consisted of 25 choice trials, each followed by a forced trial to the other alternative. Food was never presented during this session. On choice trials, both keys were illuminated white. The first response to either key more than $4 \mathrm{sec}$ after stimulus onset (FI $4 \mathrm{sec}$ ) terminated the choice stimuli and produced $4 \mathrm{sec}$ of $\mathrm{S} 1$ if the effective response had been to one key or $4 \mathrm{sec}$ of $\mathrm{S} 2$ if it had been to the other. When the contingency was met, the other key went dark. The FI 4-sec schedule was intended to minimize the effect of shortlatency responses, which might be unduly influenced by a pigeon's location in the box, from meeting the contingency. Location of S1 and S2 was counterbalanced across subjects (see Column B of Table 3). On choice trials, the keys stayed white and the contingency remained in effect until a peck produced either S1 or S2.

A forced trial followed each choice trial. Only the key on which

Table 3

A Summary of Some Aspects of the Procedure and Results for the Unconfounded Group in Experiment 2

\begin{tabular}{llcc}
\hline Subject & Column A & Column B & Column C \\
\hline UC 1 & G/A/R & A/R & 19 \\
UC 2 & G/R/A & A/R & 16 \\
UC 3 & G/A/R & R/A & 18 \\
UC 4 & G/R/A & R/A & 13 \\
UC 5 & A/R/G & R/G & 24 \\
UC 6 & R/A/G & A/G & 10 \\
UC 7 & A/R/G & G/R & 15 \\
UC 8 & R/A/G & G/A & 20 \\
UC 9 & R/G/A & A/G & 13 \\
UC 10 & A/G/R & R/G & 22 \\
UC 11 & R/G/A & G/A & 14 \\
UC 12 & A/G/R & G/R & 12 \\
Mean & & & 16.33 \\
\hline
\end{tabular}

Note-Column $A=$ (training) key light colors signaling CONC schedule, $S 1$, and $S 2$ (presented as CONC/S1/S2: $G=$ green, $A=$ amber,$R=$ red). Column $B=$ (testing) stimulus produced on left and right key (presented as left/right: $G=$ green, $A=$ amber, $R=$ red). Column $C=$ (test results) number of $S 2$ choices (overall mean $=16.33$ ). 
the contingency had not been met on the preceding trial was illuminated. That is, if the pigeon produced Sl on the preceding choice trial, it could only produce $S 2$ on the following forced trial, and vice versa. The first response to the lone white key more than $4 \mathrm{sec}$ after it had been illuminated produced the appropriate stimulus. On forced trials, this white stimulus remained on the key until a response met the contingency or until $60 \mathrm{sec}$ had passed, at which time the trial was terminated. Forced trials assured exposure of subjects to the contingencies on each key. A 16-sec interval, during which the keys were dark, intervened between the termination of S1 or S2 and the onset of the next test trial. For programming convenience, this interval was increased to $20 \mathrm{sec}$ following those forced trials on which there was no effective response.

\section{Results and Discussion}

All subjects acquired the keypeck response and maintained it throughout pretraining, training, and the 25 choice trials in the test. Table 3 summarizes the results. The important comparison is the relative preference for S1 vs. S2 on choice trials. The measure of preference employed was the number of $\mathrm{S} 2$ choices out of a maximum possible of 25. Data were recorded separately for the first 5 , middle 15 , and last 5 choice trials. Separate analyses of all 25 choice trials and the last 20 choice trials were conducted.

Column C of Table 3 shows the number of S2 choices made by each subject during the 25 choice trials. With 25 choice trials, 13 or more $\$ 2$ choices indicates an $\mathrm{S} 2$ preference, that is, that $\mathrm{S} 2$ was the more effective conditioned reinforcer. Ten of the 12 subjects showed an $\mathbf{S} 2$ preference by making more $S 2$ than S1 choices $(p=.038$, binomial expansion). However, over the last 20 free-choice trials, 9 of 11 subjects (the 12th showed no preference) made more $S 2$ than S1 choices $(p=.066$, binomial expansion). This is the only discrepancy between the analyses of the last 20 and all 25 choice trials. Across the 25 choice trials, the pigeons made a mean of $16.33 \mathrm{~S} 2$ choices, which differs significantly from the indifference point of $12.5[\mathrm{t}(11)=2.497, \mathrm{p}<.05]$. The results of Experiment 2 again indicate that $\mathrm{S} 2$ is a more effective conditioned reinforcer than S1 following S2 redundant training when confounds are eliminated.

\section{GENERAL DISCUSSION}

When controls for differential similarity of training and test cue patterns were instituted, S2 was a reliably more effective conditioned reinforcer than S1 following S1-S2-food pairings, that is, an S2 redundant procedure. This result is contrary to certain predictions made by Egger and Miller, based upon their information hypothesis. Furthermore, previous findings which have shown that an informative S1 is a more effective conditioned reinforcer than a redundant S2 may be attributed to differential generalization decrements. The role of differential generalization decrements in tests of the conditioned reinforcement value of informative S1s and redundant S2s was directly demonstrated in Experiment 1. All previous comparisons of $\mathrm{S} 1$ and $\mathrm{S} 2$ had been made with procedures that confounded the effects of differential changes in S1 and S2 context between training and test with the effects of stimuli (S1 vs. S2). Therefore, contiguity theories of conditioned reinforcement, for example, Perkin's (1981), can explain a set of results which heretofore had been thought to refute them.

Another set of experiments that have been interpreted as refuting contiguity explanations compared the conditioned reinforcing effects of informative and redundant S2s. Egger and Miller $(1962,1963)$ predicted that, following S2 redundant and S2 informative training procedures (see Figure 1), an informative $\mathrm{S} 2$ would be a more effective conditioned reinforcer than a redundant $\mathbf{S} 2$. However, in the three experiments to date that make such a comparison (Egger \& Miller, 1962, 1963; Seligman, 1966), no unequivocal evidence that informative $S 2 s$ are more reinforcing has been produced. In Egger and Miller's (1962) first experiment, rats in the two conditions showed a differential tendency to respond before the conditioned reinforcement test. Therefore, while an analysis of variance showed a significant difference between the $\mathbf{S} 2$ informative and $\mathbf{S} 2$ redundant conditions, an analysis of covariance did not. In Egger and Miller's (1963) second experiment, the procedural arrangements made it possible for a greater amount of reward (number of food pellets) to follow the informative S2 than the redundant S2. (In the S2 informative condition, an additional 15 food pellets were presented randomly during a 25 -min session with 35 trials). Finally, Seligman (1966) found that his redundant $\mathbf{S} 2$ and informative $\mathbf{2} 2$ did not differ reliably as conditioned punishers; in fact, there was a nonsignificant trend for the redundant $\mathrm{S} 2$ to be a more effective conditioned punisher than the informative $\mathbf{S 2}$. These three experiments do not provide a convincing demonstration that an informative $\mathbf{S} 2$ is a more effective conditioned reinforcer than a redundant $S 2$. In fact, this is exactly the mixed bag of results one would expect on the basis of a contiguity theory which predicts that informative and redundant $\$ 2$ s are equally reinforcing, all other things being equal.

The results of the present two experiments and a careful analysis of previous experiments show that the Egger and Miller information hypothesis, as presently formulated, is not well founded empirically. One prediction derived from the information hypothesis, specifically, that an informative $S 1$ is a more effective conditioned reinforcer than a redundant $\mathbf{S 2}$, is contrary to the facts of Experiments 1 and 2. A redundant $\mathrm{S} 2$ is a more effective conditioned reinforcer than an informative S1. Additionally, supportive experiments (Davis \& Oliphant, 1968; Egger \& Miller, 1962; McCausland et al., 1967; Seligman, 1966; and Thomas et al., 1968), which purported to show that an informative S1 was more effective, are clearly 
confounded by differential generalization decrements, as demonstrated in Experiment 1. A second prediction derived from the information hypothesis, that an informative S2 is a more effective conditioned reinforcer than a redundant $\mathbf{S}$, has not been unequivocally confirmed.

Although Egger and Miller's prediction that an informative $\mathrm{S} 1$ will be a stronger conditioned reinforcer than a redundant $\mathbf{S} 2$ has been shown to be incorrect, the information hypothesis does not necessarily predict that $\mathrm{S} 1$ will be stronger than $\mathrm{S} 2$. Consider the left-hand panel of Figure 3, which shows changes in "attractiveness" in the S2 redundant training procedure. [This curve is the inverse of the "drive level" curve of Egger and Miller's Figure 1 (1962, p. 98). I rescaled and labeled the curve "attractiveness" to avoid the activation implications of the drive concept and to emphasize the relationship of this analysis to others (Perkins 1971, 1981).] One can identify absolute and relative amounts of information or attractiveness, a distinction which Egger and Miller did not consistently maintain. In Figure 3, b and $\mathrm{d}$ represent the absolute amount of information or level of attractiveness of S1 and S2, respectively. (Egger and Miller equated absolute amount of information and drive level). However, as Egger and Miller suggested, it is not this absolute level which determines how reinforcing a stimulus is. Rather, it is the relative change in information or attractiveness signaled by the onset of a stimulus. S1 is more informative, in the relative sense, and therefore more reinforcing, because its onset produces a larger increase in information, in the absolute sense, than does the onset of S2, that is, $a-b>c-d$. This is the heart of the information hypothesis.

To predict what will occur in a test of the separate effects of S1 and S2, one must decide whether it is the reinforcing effect which generalizes to a conditioned reinforcement test (right-hand panel of Figure 3) or the absolute amount of information/attractiveness

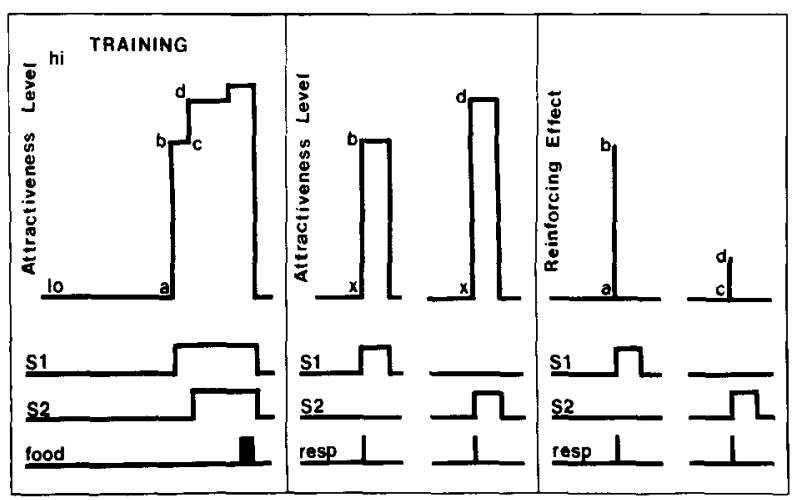

Figure 3. The theoretical effects of the onset of S1 and S2 during S2 redundant training (left-hand panel) and conditioned reinforcement tests of their separate effects (center and right hand panel). See text for explanation. which generalizes to the test (center panel of Figure 3). If we assume the former, as Egger and Miller did, then we have two rules for determining the reinforcing effect of a stimulus: the information rule and a how-reinforcing-it-was-before rule. If we assume the latter, we reapply the information rule. The stimulus that is more informative, in the relative sense, will be more reinforcing. In the test situation, $\mathrm{S} 2$ can be expected to be more reinforcing than $S 1$ because, in the new context, $x, S 2$ is more informative than $\mathrm{S} 1(\mathrm{x}-\mathrm{d}>\mathrm{x}-\mathrm{b})$. A similar analysis leads to the prediction that an informative $S 2$ should be just as reinforcing as a redundant $S 2$ if they occur in identical contexts. Using the information hypothesis consistently and taking into account changes in context yields predictions that are consistent with the data and analyses presented here. Redundant $\mathrm{S} 2 \mathrm{~s}$ are more reinforcing than informative S1s in tests of their separate effects, and there is no compelling evidence that informative $S 2 s$ are more reinforcing than redundant S2s.

These results also have implications for at least two other theories of conditioned reinforcement. Since S2 is clearly a more effective conditioned reinforcer than $\mathrm{S} 1$, these results contradict the $100 \%$ transmission of attractiveness hypothesis of Perkins (1968; however, see Perkins, 1965 and 1981, where that position is qualified in a fashion consistent with these results). Additionally, the results of Experiment 1, but not of Experiment 2, might appear to contradict Fantino's delay-reduction hypothesis (Fantino, 1977; Fantino \& Navarick, 1974). Following the calculation method suggested by Fantino and Navarick (p. 180), the value of $S 1$ relative to that of $S 1$ and $S 2$ combined is .64 in Experiment 1 but only .29 in Experiment 2. The delay reduction hypothesis would appear to predict an S1 preference in Experiment 1 and an S2 preference in Experiment 2. However, these predictions are based upon calculations of the relative value of S1 and S2 in training. However, if we base our predictions of the conditioned reinforcing effects of S1 and S2 upon the delay reductions they signal in testing, S2 should be more reinforcing. In Experiment 1, the white key in the unconfounded group signaled a 60-sec delay to reinforcement. In testing, the onset of S1 reduces a $60-\mathrm{sec}$ delay to $2 \mathrm{sec}$, while the onset of $\mathrm{S} 2$ reduces a $60-\mathrm{sec}$ delay to $1 \mathrm{sec}$ and is therefore more reinforcing.

Finally, there is some need to explain why studies of conditioned suppression with sequential stimuli (e.g., Ayres, 1966; Borgealt et al., 1972; Scheuer \& Keeter, 1969; Seger \& Scheuer, 1977-which purport to provide direct tests of the information hypothesis) are not considered pertinent to this argument. [Similarly, I have not applied these results to the Rescorla and Wagner (1972) model as some authors (e.g., Rescorla, 1972) have applied tests of the conditioned reinforcing value or sequential stimuli. Nor have I 
attempted to assimilate tests of the information hypothesis with studies of serial conditioned stimuli (e.g., Kehoe, Gibbs, Garcia, \& Gormezano, 1979, and Sears, Baker, \& Frey, 1979, two recent examples of the attempt to assimilate the two areas).] This reflects two assumptions made by this writer which do not seem to be universally accepted.

The first is that the Egger and Miller information hypothesis is a reinforcement theory and not a theory of Pavlovian conditioning. The Egger and Miller hypothesis attempts to explain differences in the ability of stimuli to reinforce (in the operant sense) antecedent responses; it does not attempt to explain differences in the ability of stimuli to elicit behavior during those stimuli. The second is that conditioned reinforcement measures are not equivalent to Pavlovian measures. Conditioned responses (CRs) do not measure the conditioned reinforcing properties of the stimuli which elicit them. Pavlovian measures may not be predictive of the conditioned reinforcing value of a stimulus. Obviously, conditioned reinforcement and Pavlovian conditioning often share a procedural similarity, that is, the sequential pairing of stimuli, one that is usually neutral followed by another that is a primary reinforcer. However, Pavlovian measures are measures of reactions during the neutral stimulus, while conditioned reinforcement measures are measures of changes in the strength of responses that occur before the stimulus.

Most theorists seem to implicitly or, in a few cases, explicitly (e.g., Gray, 1975, pp. 175-187; Hull, 1943, pp. 97-98) assume that Pavlovian and conditioned reinforcement measures are interchangeable or equivalent, that is, that the magnitude of conditioned responses produced by stimuli and the reinforcing properties of stimuli are proportional. I do not. In fact, there are numerous reasons to believe that these two measures are not equivalent. Schneiderman (1972) and Sears, Baker, and Frey (1979) have shown that the occurrence of a CR during a stimulus is controlled by the temporal relationship between that CR and the primary reward signaled by that stimulus. Conditioned responses may occur because of the mitigating effect those responses have on the unconditioned stimulus; that is, conditioned responses may be preparatory (Perkins, 1971). As such, the strength with which stimuli elicit conditioned responses would seem to be influenced by stimulus-reinforcer temporal relationships which probably are not related to the conditioned reinforcing properties of those stimuli. Likewise, when multiple CR measures are being taken during a single stimulus and those measures diverge, contradictory predictions of conditioned reinforcing strength are produced.

In summary, these two experiments provide evidence that, in unconfounded tests of the conditioned reinforcement value of sequential stimuli, redundant $S 2 \mathrm{~s}$ will be more reinforcing than informative S1s in tests of their separate effects. This result is consistent with contiguity theories of conditioned reinforcement. Previous studies, which found that $\mathrm{S} 1$ was more reinforcing and would otherwise refute contiguity theories, were shown to be confounded by the effects of differential generalization decrement. Finally, I have demonstrated that an internally consistent version of the Egger and Miller information hypothesis predicts the observed S2 preference.

\section{REFERENCE NOTE}

1. Fleshler, M., \& Hoffman, H. S. A progression for generating variable interval schedules in which the probability of reinforcement as a function of time since reinforcement is constant (Research Bulletin No. 26). University Park: Pennsylvania State University, 1962.

\section{REFERENCES}

Ayers, J. J. B. Conditioned suppression and the information hypothesis. Journal of Comparative and Physiological Psychology, 1966, 62, 21-25.

BAKER, T. W. Component dynamics within compound stimuli. In R. F. Thompson \& J. F. Voss (Eds.), Topics in learning and performance. New York: Academic Press, 1972.

Borgealt, A. J., Donahoe, J. W., \& Weinstein, A. Effects of delayed and trace components of a compound CS on conditioned suppression and heart rate. Psychonomic Science, 1972, 26, 13-15.

Davis, J. D., \& Oliphant, C. A test of information theory of secondary reinforcement. Proceedings of the 76th Annual Convention of the American Psychological Association, 1968, 137-138.

EgGER, M. D., \& Mtluer, N. E. Secondary reinforcement in rats as a function of information value and reliability of the stimulus. Journal of Experimental Psychology, 1962, 64, 97-104.

EgGer, M. D., \& Miller, N. E. When is a reward reinforcing?: An experimental study of the information hypothesis. Journal of Comparative and Physiological Psychology, 1963, 56, 132-137.

Fantino, E. Conditioned reinforcement: Choice and information. In W. K. Honig \& J. E. R. Staddon (Eds.), Handbook of operant behavior. New York: Prentice-Hall, 1977.

Fantino, E., \& Navarick, D. Recent developments in choice. In G. Bower (Ed.), The psychology of learning and motivation (Vol. 8). New York: Academic Press, 1974.

Gray, J. A. Elements of a two-process theory of learning. New York: Academic Press, 1975.

Hull, C. L. Principles of behavior. New York: Appleton-CenturyCrofts, 1943.

Kenoe, E. J., Gibbs, C. M., Garcia, E., \& Gormezano, I. Associative transfer and stimulus selection in classical conditioning of the rabbit's nictitating membrane response to serial compound CSs. Journal of Experimental Psychology: Animal Behavior Processes, 1979, 5, 1-18.

MARsh, G. O. Inverse relationship between discriminability and stimulus generalization as a function of number of test stimuli. Journal of Comparative and Physiological Psychology, 1967, 64, 284-289.

McCausland, D. F., Menzer, G. W., Dempsey, T. K., \& Birkimer, J. C. Response-contingent and noncontingent informative and redundant secondary reinforcers. Psychonomic Science, 1967, 8, 293-294.

Miller, N. E. Analytical studies of drive and reward. American Psychologist, 1961, 16, 739-754. 
Perkins, C. C., JR. A conceptual scheme for studies of stimulus generalization. In D. J. Mostofsky (Ed.), Stimulus generalization. Stanford, Calif: Stanford University Press, 1965.

Perkins, C. C., JR. An analysis of the concept of reinforcement. Psychological Review, 1968, 75, 155-172.

Perkins, C, C., JR. Reinforcement in classical conditioning. In H. H. Kendler \& J. T. Spence (Eds.), Essays in neobehaviorism: A memorial volume to Kenneth $W$. Spence. New York: Appleton-Century-Crofts, 1971.

Perkins, C. C. The analysis of performance. In M. D. Zeiler \& P. Harzem (Eds.), Advances in analysis of behaviour (Vol. 3): Biological factors in learning. Chichester, England: Wiley, 1981.

ResconlA, R. A. Informational variables in Pavlovian conditioning. In G. H. Bower \& J. T. Spence (Eds.), The psychology of learning and motivation (Vol. 6). New York: Academic Press, 1972.

Rescorla, R. A., \& Wagner, A. R. A theory of Pavlovian conditioning: Variations in the effectiveness of reinforcement and nonreinforcement. In A. H. Black \& W. F. Prokasy (Eds.), Classical conditioning II: Current research and theory. New York: Appleton-Century-Crofts, 1972.

Scheuer, C., \& KeEter, W. H. Temporal vs. discriminative factors in the maintenance of conditioned suppression: A test of the information hypothesis. Psychonomic Science, 1969, 15, 21-22.

Schneiderman, N. Response system divergencies in aversive classical conditioning. In A. H. Black \& W. F. Prokasy (Eds.), Classical conditioning II: Current research and theory. New York: Appleton-Century-Crofts, 1972.

Sears, R. J., Baker, J. S., \& Frey, P. W. The eye blink as a time locked response: Implications for serial and second-order conditioning. Journal of Experimental Psychology: Animal Behavior Processes, 1979, 5, 43-64.

Seger, K. A., \& Scheuer, C. The information properties of S1, $\mathrm{S} 2$, and the S1-S3 sequence on conditioned suppression. Animal Learning \& Behavior, 1977, 5, 39-41.

Seligman, M. E. P. CS redundancy and secondary punishment. Journal of Experimental Psychology, 1966, 72, 546-550.

Stubis, D. A., \& Pliskoff, S. S. Concurrent responding with fixed relative rate of reinforcement. Journal of the Experimental Analysis of Behavior, 1969, 12, 887-895.

Thomas, D. R., Berman, D. L., Serednesky, G. E., \& Lyons, J. Information value and stimulus configuring as factors in conditioned reinforcement. Journal of Experimental Psychology, $1968,76,181-189$.

Winer, B. J. Statistical principles in experimental design. New York: McGraw-Hill, 1971.

\section{NOTE}

1. Based on the material in chapter 7 of Winer (1971), the following formula was derived to test within-subject means with unequal ns: $F=\left(A_{i} B_{1}-A_{i} B_{2}\right)^{2} / 2$ (MS error within subjects $\left./ \bar{n}\right)$, where $A_{i} B_{1}$ and $A_{i} B_{2}=$ cell means for the two levels of the within-subject variable (B) at the $\mathrm{i}^{\text {th }}$ level of the between-subject variable $(A)$, and $\overline{\mathrm{n}}=$ the harmonic mean number of subjects per group.

(Manuscript received June 4, 1980; revision accepted for publication September 23, 1981.) 